\title{
Estimando o desalinhamento cambial brasileiro: uma análise de robustez a partir do modelo global com meca- nismo de correção de erros *
}

\author{
Emerson Fernandes Marçal \\ Professor (EESP-FGV/SP e CCSA-Mackenzie) \\ Endereço: Rua Itapeva, 286 - 10 andar - São Paulo/SP - Brasil \\ CEP: 01332-000 - E-mail: emerson.marcal@fgv.br \\ Recebido em 23 de julho de 2013. Aceito em 24 de novembro de 2014.
}

\begin{abstract}
Resumo
O presente trabalho tem por objetivo comparar duas metodologias para cálculo de desalinhamento cambial. A primeira metodologia consiste na estimação do desalinhamento cambial a partir de técnicas multivariadas de séries de tempo nas quais apenas variáveis associadas ao país em análise são utilizadas na modelagem. A segunda metodologia consiste na utilização de fatores globais, como sugerido pelo Modelo Vetorial Autorregressivo com Correção de Erros Global (VAR-MCEG). O caso brasileiro é analisado a partir das duas metodologias. Os resultados sugerem que as estimativas podem diferir em magnitude para diferentes períodos. Ambas as metodologias sugerem que o canal pelo qual termos de troca afetam a taxa de câmbio real brasileiro é indireto. Melhorias de termos de troca levam a uma melhora da posição internacional de investimento e, logo, geram uma valorização da moeda brasileira. Os resultados da metodologia GVECM sugerem que a taxa de câmbio real brasileira é afetada no longo prazo pelo nível de taxa de câmbio real dos seus parceiros comerciais.
\end{abstract}

\section{Palavras-Chave \\ VECM global. Cointegração.}

\begin{abstract}
This paper aims to compare two different methodologies to estimate exchange rate misalignment. The first methodology consists of using multivariate time series techniques and a model with domestic variables. The second methodology consists of Pesaran's Global Error Correction Model with global factors (GVECM). The Brazilian case is analyzed using these two methodologies. The results of exchange misalignment estimates are different particularly in their magnitude terms but not in their signs. Both methodologies suggest that the channel by which terms of trade affect exchange rate is indirect. Improvement in Brazilian terms of trade induces improvement in net foreign investment position by affecting current account result. These improvements also induce a real exchange rate appreciation in the long run. In recent period, this channel appears to play an important role in explaining Brazilian exchange rate fundamental improvement. The results from GVECM suggest that the level of Brazilian real exchange rate is linked to the level of real exchange of its main trading partners.
\end{abstract}

- Este artigo é produto do Projeto Regulação do Comércio Global, da Diretoria de Estudos e Relações Econômicas e Políticas Internacionais (Dinte) do Ipea. 


\section{Keywords}

GVECM. Cointegration.

\section{JEL Classification}

F31. C32.

\section{Introdução}

A taxa de câmbio é um preço macroeconômico importante, e sua flutuação gera efeitos sobre atividade econômica, preços e taxa de juros, bem como repercussões setoriais e sobre fluxos de comércio. Grandes flutuações da taxa de câmbio sempre geram debates sobre em que medida esses movimentos são "excessivos" e se refletem "fundamentos" ou se são "racionais".

A literatura empírica sobre o tema tem avançado na direção da construção de modelos que permitem avaliar os determinantes de longo prazo das taxas de câmbio reais. Estratégias empíricas podem ser formuladas com base em modelos que utilizam a doutrina da Paridade do Poder de Compra (PPC) ou uma análise baseada em fundamentos (Clark e MacDonald, 1998). Em geral, os trabalhos utilizam técnicas de séries de tempo em que a interdependência entre os países não é modelada como regra ou técnicas de painel em que também o espaço para interelações entre os países é limitado. Técnicas de painel possuem o agravante de impor similaridades não testadas necessariamente entre os parâmetros dos países. Hossfeld (2009) faz uma revisão dos trabalhos de séries de tempo e painel aplicados à metodologia de desalinhamento cambial.

Este trabalho procura avaliar em que medida a taxa de câmbio real brasileira sofre influência dos seus próprios fundamentos e da evolução de fundamentos dos principais parceiros comerciais brasileiros. A metodologia aplicada é similar à apresentada por Hashen Pesaran (Pesaran e Smith, 2006; Pesaran et al., 2002; Pesaran et al., 2001).

O trabalho está dividido nas seguintes seções. Além desta introdução, na seção 2 é discutida a motivação para a realização dos testes do trabalho. Uma revisão não exaustiva da literatura de desalinhamento cambial é realizada na seção 3 . Na seção 4, a metodologia econométrica utilizada é discutida em maior detalhe. Na seção 5, 
encontra-se a base de dados. Na seção 6, os resultados são apresentados, e é feita a comparação com estudos semelhantes encontrados na literatura. Na seção 7, as conclusões finais são extraídas.

\section{Motivação para estimar um modelo global}

A severidade da crise da economia americana em 2008 trouxe o temor de um forte contágio negativo para o resto do mundo. ${ }^{l}$ As autoridades americanas adotaram, entre outras medidas, uma política monetária agressiva com forte redução das taxas de juros nominais e expansão monetária. Isso teria gerado uma forte pressão para a depreciação da moeda americana frente a moedas cujas taxas de juros domésticas não acompanharam esse mesmo movimento. No caso em que os países acompanharam tal redução ou que mantiveram suas taxas de juros inalteradas e optaram por acumular reservas para evitar a apreciação de sua moeda, acabaram "importando" pressões inflacionárias. Alguns autores argumentam que os Estados Unidos estariam tentando utilizar sua política monetária para gerar uma depreciação de sua moeda e, com isso, criar um estímulo de demanda agregada que contribuiria para tornar a recessão interna mais curta e menos intensa. Essa política gera repercussões no resto do mundo, e há uma discussão sobre em que medida esses efeitos seriam deletérios.

O mecanismo pelo qual a política monetária operaria seria via depreciação da taxa de câmbio real americana frente a seus parceiros importantes. Caso o efeito sobre os demais países fosse deletério, estes tentariam utilizar o mecanismo a sua disposição para evitar que a moeda local se apreciasse tal como acumulação de reservas, taxação de influxo de capitais, entre outros. Seria configurada uma política denominada na literatura beggar thy neighbor (Eichengreen e Sachs, 1986), em que os países tentariam evitar a apreciação de sua moeda para evitar internalizar os custos de uma política monetária deliberadamente expansionista (quantitative easing) (Ugai, 2007).

\footnotetext{
1 O termo contágio, em geral, na literatura de crises financeiras, deve ser interpretado como um evento que gerou efeitos negativos de propagação acima do esperado por algum mecanismo de propagação tradicional. A noção de interdependência diz respeito ao mecanismo de propagação tradicional. O foco deste trabalho está neste segundo conceito. Um exemplo de trabalho que foca no primeiro conceito pode ser encontrado em Marçal et al. (2011).
} 
Num ambiente intertemporal, em que os custos e benefícios de uma política devem ser avaliados não só pelos efeitos de curto prazo, mas também sobre produto, inflação e bem-estar dos países, o comportamento estratégico destes deve ser analisado para avaliar em que condições vale a pena para um país adotar uma estratégia de promoção de uma política monetária excessivamente frouxa para tentar obter ganhos de curto prazo, em termos de atividade econômica, e estar exposto a sofrer algum tipo de retaliação dos demais parceiros. Cabe analisar em que situação é ótimo aos parceiros de um país não retaliar e aceitar os custos de uma depreciação de um parceiro comercial importante como melhor estratégia.

No caso de um país pequeno, talvez a estratégia de tentar retaliar não seja a melhor resposta, na medida em que se torna muito difícil causar danos significativos ao país líder, de modo que tal política seria ineficaz. O principal mecanismo pelo qual a política monetária agiria seria via desvalorização da taxa de câmbio, e, para o país seguidor, seria difícil, com sua própria política monetária, contrabalançar os efeitos para apreciação cambial. Turnovsky et al. (1987) são um exemplo de trabalho em que a interação estratégica é formalmente analisada.

Dado que o mecanismo pelo qual a política monetária frouxa opera é através de uma depreciação excessiva da moeda do país, e que a duração é o mecanismo pelo qual as exportações líquidas reagiriam no curto prazo, gerando um ganho de demanda agregada que suavizaria flutuações do produto em torno de seu nível potencial, algumas questões empíricas se apresentam: a) Em que medida uma política monetária é capaz de gerar um movimento de desalinhamento cambial expressivo; b) Qual a duração do mesmo; c) Desalinhamentos expressivos de um país podem ser rapidamente contrabalançados por políticas similares dos parceiros comerciais relevantes ao país ou, dito de outra forma, que o desalinhamento cambial de um país é acompanhado de desalinhamentos em direção contrária em quais países; d) Quais os efeitos em termos de bem-estar de tais políticas (Turnovsky, Basar et al. (1987)) e; e) Em que medida políticas cambiais estariam na gênese de crises cambiais (Glick e Rose (1998)).

Dessa forma, a pesquisa sobre a existência de interdependência entre os movimentos de câmbio dos diversos países é importante para um melhor entendimento dos canais pelos quais choques das mais diversas ordens se propagam e também para analisar como países específicos são influenciados por estes movimentos. 


\section{Literatura de desalinhamento cambial}

A literatura sobre taxa de câmbio real é de longa data. A doutrina clássica e mais antiga para a determinação da taxa de câmbio real é a PPC. Referência a esta teoria pode ser encontrada em autores clássicos. Recentemente, uma série de estudos veio confirmar a validade da PPC para os bens transacionáveis, embora o ajustamento se dê de forma bem lenta (Froot e Rogoff, 1995). Ahmad e Craighead (2010), num trabalho recente, com dados mensais e de preços ao consumidor para uma base longa, secular, mensal entre Estados Unidos e Reino Unido, demonstram evidência de forte reversão à média, mas com alta meia-vida. O trabalho segue a linha proposta por Taylor (2001).

\subsection{A economia do desalinhamento}

Há uma discussão teórica sobre quais são as variáveis que determinam os fundamentos de longo prazo da taxa de câmbio. Uma literatura mais antiga remonta ao trabalho de Edwards (1987) e Dornbusch (1976). O primeiro analisa a denominada "economia do desalinhamento", suas causas e consequências. Já o segundo trata do modelo clássico de câmbio flexível, em que choques de política monetária causam variações além dos fundamentos (PPC) de longo prazo.

Os trabalhos de Bilson (1979) e Mussa (1976) também são clássicos e contemplam a denominada "abordagem monetária" para a taxa de câmbio. Segundo esta abordagem, a taxa de câmbio seria basicamente determinada por conta da evolução relativa do produto e da oferta de moeda entre os países na hipótese de validade contínua da PPC e da Paridade da Taxa de Juros Descoberta (PTJD), assim como da estabilidade na demanda por moeda dos países. O trabalho de Meese e Rogoff (1983) colocou em dúvida o poder explicativo dessa teoria ao mostrar que as previsões obtidas a partir de tal abordagem não são superiores a um modelo "ingênuo", como um passeio aleatório puro para a taxa de câmbio. Stein (1995) propõe a abordagem da taxa natural de câmbio - Natural Real Exchange Rate (Natrex). Segundo o autor, nessa abordagem, o câmbio de equilíbrio é aquele que iguala a poupança ao nível de investimento gerado pelos fundamentos econômicos. 
Uma discussão mais recente sobre desalinhamento é feita em Williamson (1994). Nela, afirma-se que o câmbio de equilíbrio é aquele que permite ao país manter um determinado déficit ou superávit desejado (visto como sustentável) nas contas externas. Esta é a denominada Abordagem Fundamental da Taxa de Câmbio Real - Fundamental Real Exchange Rate Approach (FRER). Outra referência mais recente desta abordagem é Cline (2008). Uma crítica a ela advém do fato de existir um alto grau de arbitrariedade por conta da subjetividade na escolha da meta de contas externas. Além disso, esse tipo de abordagem centra o foco nos fluxos, e não nos estoques.

Faruqee (1995) procura incorporar questões relacionadas à evolução dos estoques e constrói um modelo que permite uma interação entre fluxos e estoques. Dessa forma, mostra que deve existir uma relação estável entre o câmbio real e a posição externa líquida de ativos e passivos entre residentes e não residentes. Esta é a denominada Abordagem Comportamental da Taxa de Câmbio Real - Behavioural Real Exchange Rate Approach (BRER). O modelo é estendido por Alberola et al. (1999).

Kubota (2009 a e b) utiliza um modelo com agente representativo que maximiza consumo intertemporalmente e acumula capital e tem como resultado que a taxa de câmbio real é função de termos de troca, posição externa líquida e produtividade relativa dos setores transacionáveis e não transacionáveis. Esta abordagem, que é a utilizada no trabalho, procura diminuir o grau de subjetividade existente na estimação do desalinhamento cambial, ligando a taxa de câmbio real ao conjunto de fundamentos, a partir de algum modelo teórico, e decompor as séries de câmbio real e dos fundamentos em componentes transitórios e permanentes, utilizando alguma técnica econométrica disponível como, por exemplo, vetores autorregressivos com mecanismo de correção de erros.

\section{Metodologia econométrica}

Os modelos foram estimados utilizando-se uma abordagem tradicional para calcular desalinhamento cambial, com o emprego de uma lista de fundamentos dados pela posição externa líquida (PEL) como proporção do Produto Interno Bruto (PIB) e de um indicador de 
produtividade relacionado ao efeito Balassa-Samuelson e termos de troca que seguem estritamente a recomendação da literatura de desalinhamento (Alberola et al., 1999; Nilsson, 2004; Kubota, (2009) entre outros). Neste trabalho, propõe-se testar se estes modelos podem ser melhorados a partir da introdução de fatores globais que levam em conta uma possível interdependência entre os diversos países.

\subsection{Abordagem tradicional}

O ponto de partida será um modelo dado pelo trabalho de Johansen e Juselius (Johansen, 1988; Johansen, 1995; Juselius, 2009). Seja $X_{\mathrm{t}}=\left[\begin{array}{ll}R E R_{t} & \text { Fundamento }_{t}\end{array}\right]$ que contém o dado de câmbio real e seus fundamentos no instante $t$ para o país em análise.

O modelo geral é dado pela Equação (1):

$$
\Delta \mathbf{X}_{\mathbf{t}}=\Gamma_{1} \Delta \mathbf{X}_{\mathbf{t}-1}+\ldots+\Gamma_{k} \Delta \mathbf{X}_{\mathbf{t}-k}+\Phi \mathbf{D}_{\mathbf{t}}+\alpha \beta^{\prime} \mathbf{X}_{\mathbf{t}-\mathbf{1}}+\varepsilon_{t}
$$

em que $\varepsilon_{t}$ são erros aleatórios; e $\Omega$ é a respectiva matriz de variância e covariância dos choques. Os choques entre os países podem ser supostos não correlacionados temporal e contemporaneamente para reduzir o espaço de parâmetros a ser estimado. O vetor $\mathbf{X}_{\mathbf{t}}$ contém as séries de dados do país em análise; $\mathbf{D}_{\mathbf{t}}$ contém termos deterministas; e $\theta=\left\{\Gamma_{1}, \ldots, \Gamma_{k}, \Phi, \alpha, \beta\right\}$ denota o conjunto de parâmetros a serem estimados.

\subsubsection{Decomposição de Gonzalo e Granger}

Uma série de decomposições foram propostas para separar um processo entre componentes transitórios e permanentes. Em geral, a decomposição tem a seguinte forma: ${ }^{2}$

$$
X_{t}=\beta_{\perp}\left(c^{\prime} \beta_{\perp}\right)^{-1} c^{\prime} X_{t}+c_{\perp}\left(\beta^{\prime} c_{\perp}\right)^{-1} \beta^{\prime} X_{t}
$$

${ }^{2} \beta_{\perp}$ denota o vetor ortogonal a $\beta$ de tal sorte que $\beta^{\prime}{ }_{\perp} \beta=0$. 
As decomposições variam de acordo com a escolha do vetor $c$. Uma condição para a existência da decomposição é que a matriz $\left(\beta^{\prime} c_{\perp}\right)$ tenha posto completo. Nem sempre isso está assegurado. Gonzalo e Granger (1995) propuseram $c=\alpha_{\perp} \cdot{ }^{3}$ Esta representação sempre existe para o caso de um Modelo Vetorial com Correção de Erros (VECM) de ordem 0. Johansen (1995) propõe $c=\alpha_{\perp} \Gamma$. Esta decomposição sempre existe desde que, no sistema, haja variáveis cuja ordem de integração seja no máximo $1 .{ }^{4}$ Kasa (1992) propõe $c=\beta_{\perp}$. Outra possibilidade consiste em gerar previsões a partir do VECM estimado para cada um dos pontos. Os valores para os quais as séries convergirem são denominados fundamentos. ${ }^{5}$

Neste trabalho, utiliza-se a decomposição de Gonzalo e Granger (1995). Os autores demonstram que, em sua decomposição, os componentes transitórios não causam, no sentido de Granger, ${ }^{6}$ a variação dos componentes permanentes no longo prazo, ou seja, o desalinhamento, definido como sendo o componente transitório da equação do câmbio real num sistema multivariado, não contém informação relevante para prever a variação dos componentes permanentes no longo prazo. ${ }^{7}$ A decomposição de Gonzalo e Granger é amplamente utilizada na literatura de desalinhamento cambial (Alberola et al., 1999).

\subsection{Abordagem do GVECM}

A estratégia de modelagem do Global Vector Error Correction Model (GVECM) segue em linhas gerais o trabalho de Pesaran e coautores (Dees et al., 2007) no qual fatores globais são adicionados ao modelo tradicional VECM de forma que a ligação entre os países e eventos numa região, ou no mundo, seja explicitamente modelada.

\footnotetext{
3 A decomposição de Gonzalo e Granger (1995) é implementada no software Matlab.

${ }^{4}$ Note-se que, em (2), a matriz $C=\beta_{\perp}\left(\alpha_{\perp} \Gamma \beta_{\perp}\right)^{-1} \alpha_{\perp}^{\prime}$ existe e, para isso, a matriz $\alpha_{\perp} \Gamma \beta_{\perp}$ deve possuir inversa. Isso é uma implicação direta do teorema de representação de GrangerJohansen (Johansen, 1995).

${ }^{5}$ Neste caso, os componentes deterministas do modelo, como constante e tendência, devem estar restritos ao espaço de cointegração.

${ }^{6}$ Para uma definição rigorosa de causalidade de Granger, ver Hendry (1995).

${ }^{7}$ Se o VECM adequado contiver apenas o mecanismo de erros e termos deterministas, então a decomposição de Gonzalo e Granger (1995) satisfaz a condição para ser uma decomposição da classe proposta por Beveridge e Nelson (1981).
} 
O modelo geral é dado pela Equação (3):

$$
\Delta \mathbf{X}_{\mathbf{t}}=\sum_{i=1}^{k-1} \Gamma_{k} \Delta \mathbf{X}_{\mathbf{t}-i}+\Phi \mathbf{D}_{\mathbf{t}}+\alpha \beta_{o}^{\prime} \mathbf{X}_{\mathbf{t}-\mathbf{1}}+\alpha \beta_{1}^{\prime} Z_{\mathbf{t}-\mathbf{1}}+\sum_{i=1}^{k-1} \Theta_{k} \Delta Z_{\mathbf{t}-i}+u_{t}
$$

em que $u_{t}$ são erros aleatórios não correlacionados temporalmente; e $\Omega^{*}$ é a respectiva matriz de variância e covariância dos choques. Os choques entre os países podem ser supostos não correlacionados temporal e contemporaneamente para reduzir o espaço de parâmetros a ser estimado. O vetor $\mathbf{X}_{\mathbf{t}}$ contém as séries de dados do país em análise; $\mathbf{D}_{\mathbf{t}}$ contém termos deterministas; $Z_{\mathbf{t}}$ contém as variáveis globais; e $\theta=\left\{\Gamma_{1}, \ldots, \Gamma_{k}, \Phi, \alpha, \beta_{1}, \beta_{2}, \Theta_{1}, \ldots, \Theta_{k},\right\}$ denota o conjunto de parâmetros a serem estimados. O modelo dado por (3) exige que haja exogeneidade rraca $^{8}$ da variável $Z$ com relação aos parâmetros de interesse. Esta hipótese deve ser testada para avaliar em que medida os resultados do modelo estimado possuem propriedades estatísticas desejadas.

As séries que servirão de proxy para o termo global de um país são construídas a partir de alguma média ponderada das variáveis dos diversos países relevantes para a análise. Em geral estes pesos podem ser dados pela relevância do parceiro comercial, pelo tamanho das economias seja no comércio, seja na produção global, entre outros. No caso deste trabalho, os pesos utilizados serão dados pela participação de cada país no total de comércio brasileiro, país foco da análise

$$
\begin{aligned}
& Z_{t}=\left[\begin{array}{lllll}
z_{1 t} z_{2 t} & \ldots & \ldots & z_{k-1, t} & z_{k, t}
\end{array}\right] \\
& z_{1 t}=V_{t} W_{t}
\end{aligned}
$$

na qual $V_{t}$ contém as séries de determinada variável para um conjunto de países; e $W_{t}$ consiste no conjunto de pesos utilizados. ${ }^{9}$

\footnotetext{
8 A definição de exogeneidade fraca pode ser encontrada em Hendry (1995).

${ }^{9}$ Sobre este ponto, ver Pesaran et al. (2001).
} 


\section{Base de dados}

Os dados para realização deste trabalho foram coletados na base do International Financial Statistics (IFS) do Fundo Monetário Internacional (FMI). A taxa de câmbio real para cada país é calculada a partir de uma cesta de moedas, coletadas pelo FMI, com dados de preços ao consumidor. Utilizam-se os índices de preços ao consumidor. Os dados de posição externa líquida e de reservas são levantados no FMI, a partir de 2000; e para os anos anteriores, na base de Lane e Milesi-Ferretti (2007). Os informes sobre o PIB foram coletados na base de dados do Banco Mundial, World Development Indicators, disponível on line.

As estimações foram feitas utilizando o software Oxmetrics 6.0. A frequência dos dados é anual. Em muitos dos casos, os dados iniciam-se em 1970 e terminam em 2011. Em alguns casos, a amostra inicia-se em 1980 e vai até 2011. Os países que fazem parte da base de dados são Austrália, Argentina, Brasil, Canadá, China, Colômbia, Dinamarca, Finlândia, França, Alemanha, Grécia, Índia, Itália, Portugal, Irlanda, Japão, México, Holanda, Coreia do Sul, África do Sul, Cingapura, Espanha, Suécia, Reino Unido, Uruguai, Turquia e Estados Unidos. Nem todos os países possuem dados desde 1970 até hoje. Todos os listados possuem amostra completa pelo menos a partir de 1980. Os dados da composição do comércio também foram coletados para todos os países. A série de termos de troca foi coletada junto a Fundação Centro de Estudos do Comércio Exterior (Funcex).

O indicador de preços relativos construído para corrigir o denominado efeito Balassa-Samuelson (Balassa, 1964; Samuelson, 1964) segue estritamente a metodologia proposta por Alberola et al. (1999), Nilsson (2004) e Kubota (2009) e reproduzida na Equação (6).

$$
B S_{t}=\sum_{i=1}^{N} w_{i t}\left(\frac{I P A_{B R A, t} / I P C_{B R A, t}}{I P A_{i t} / I P C_{i t}}\right)
$$




\subsection{Séries brasileiras}

A evolução temporal das séries brasileiras de câmbio real, posição internacional de investimento, indicador de preços relativos e termos de troca, pode ser vista no Gráfico 1 (em nível) e Gráfico 2 (em primeira diferença). A taxa de câmbio real brasileira apreciou-se fortemente desde 2002, como pode ser visto nos Gráficos 1A e 2A. Esse movimento foi acompanhado da melhoria da posição internacional de investimento como proporção do PIB (Gráficos 1B e 2 B). A série termos de troca (Gráficos 1D e 2 D) apresenta também uma melhoria expressiva nos últimos anos. O termo associado ao efeito Balassa-Samuelson (Gráficos $1 \mathrm{C}$ e $2 \mathrm{C}$ ) parece não ter sofrido grandes alterações no período do final da amostra.

\subsection{Série do GVECM para o Brasil: componente global}

As séries que irão compor o termo global da equação brasileira são mostradas no Gráfico 3. A primeira série (Gráfico 3A) consiste na média ponderada das taxas de câmbio reais efetivas dos parceiros comerciais brasileiros produzida pelo FMI. Os índices utilizados são do FMI. Os pesos utilizados são dados pela participação do comércio brasileiro de cada destino. Desta forma, a primeira série indicaria se os parceiros comerciais brasileiros estão valorizando ou desvalorizando sua moeda com relação à cesta relevante para cada país. Caso haja um movimento de depreciação generalizado entre os parceiros brasileiros de suas respectivas moedas, então, muito provavelmente haverá uma pressão para a apreciação da moeda brasileira. Logo, o sinal esperado para a relação de longo prazo entre o câmbio real brasileiro e tal indicador é negativo.

A segunda série (Gráfico 3B) mostra a média da evolução da posição internacional de investimento dos parceiros comerciais brasileiros. Esta média era negativa e com tendência decrescente até meados dos anos 2000. A partir de então, a tendência de queda é revertida, e a variável passa a ser positiva muito por conta da queda da importância dos Estados Unidos - com uma posição internacional de investimento deficitária - como parceiro comercial brasileiro e da ascensão da China, que tem uma posição internacional de investimentos positiva e crescente nos últimos anos. 
Por fim, a terceira série (Gráfico $3 \mathrm{C}$ ) diz respeito à evolução da média ponderada da variável proxy para o efeito Balassa-Samuelson. Esta série apresentou pouca variação no período recente.
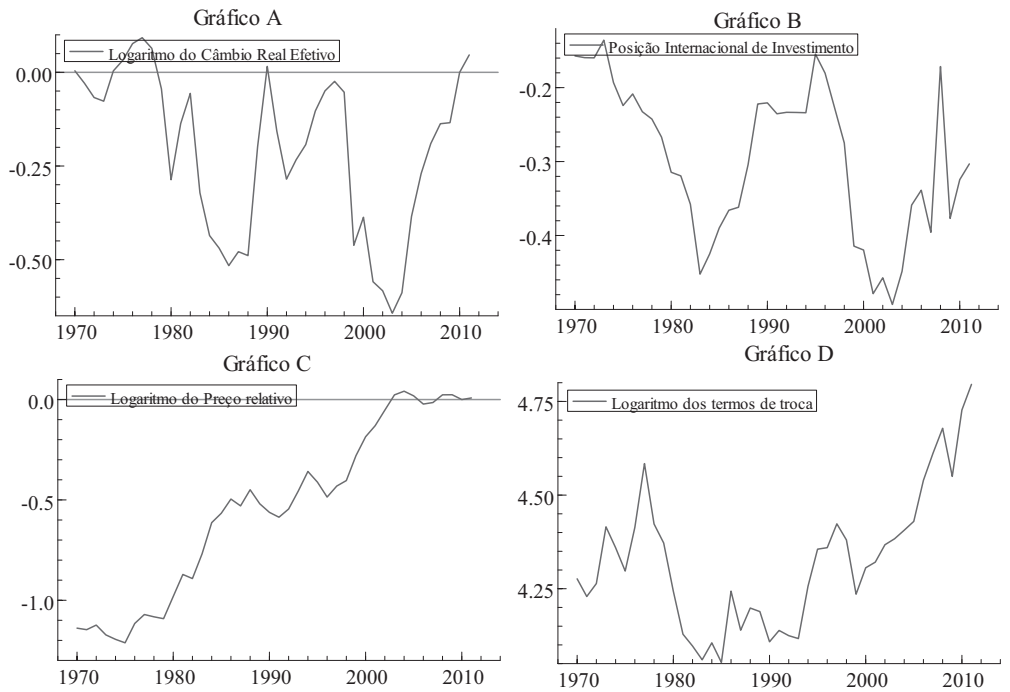

Gráfico 1 - Evolução, em nível, das séries brasileiras
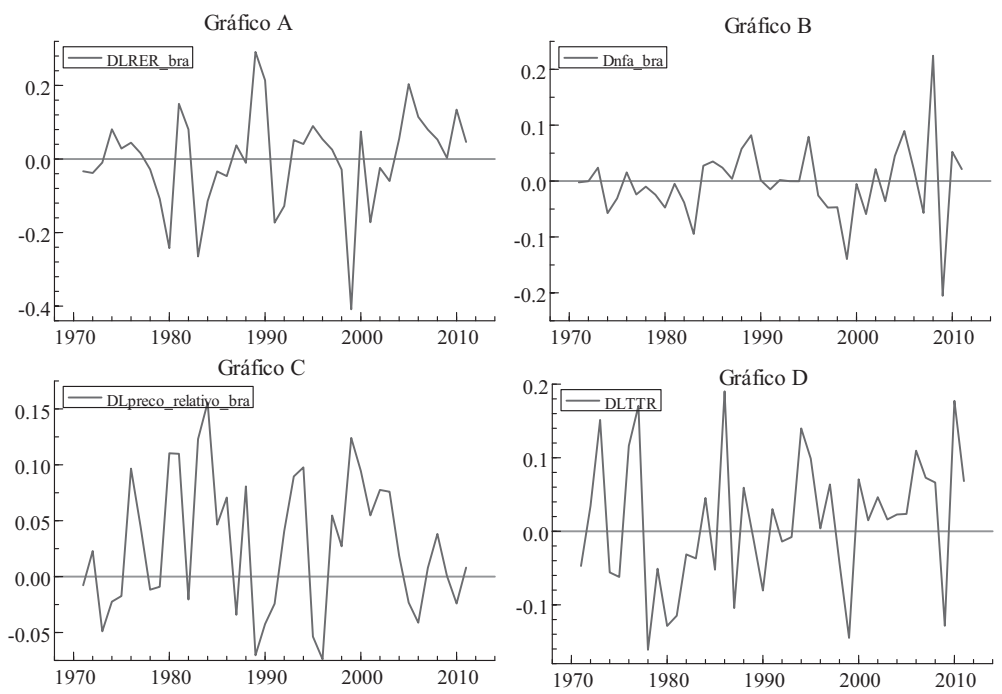

Gráfico 2 - Primeira diferença das séries brasileiras 

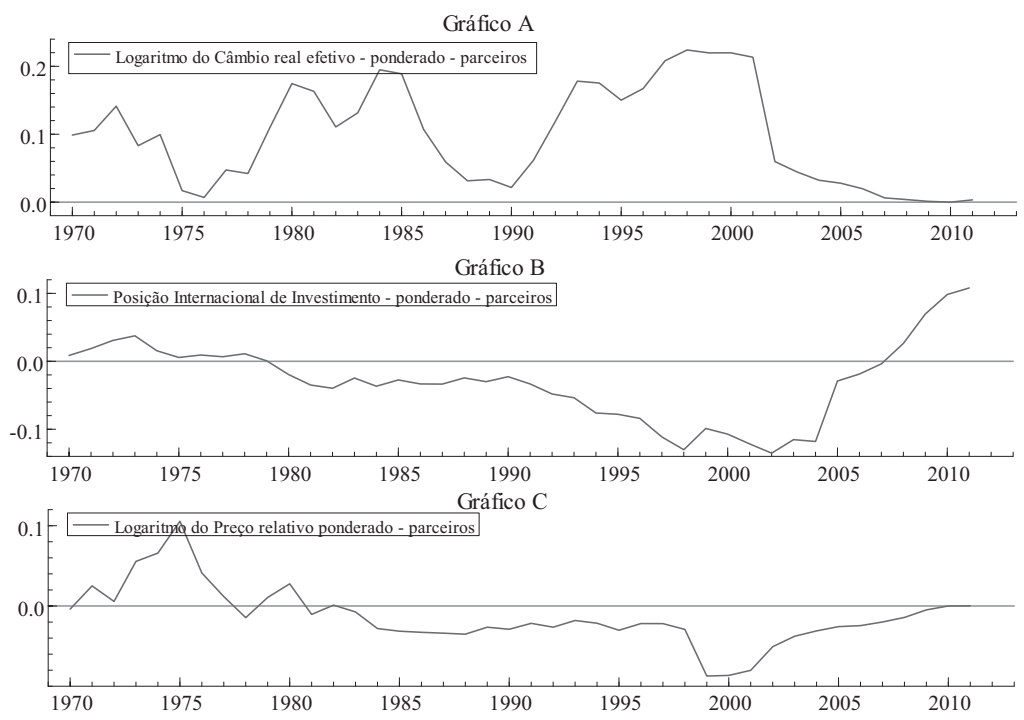

\section{Gráfico 3 - Séries que compõem o fator brasileiro do VAR-MCEG}
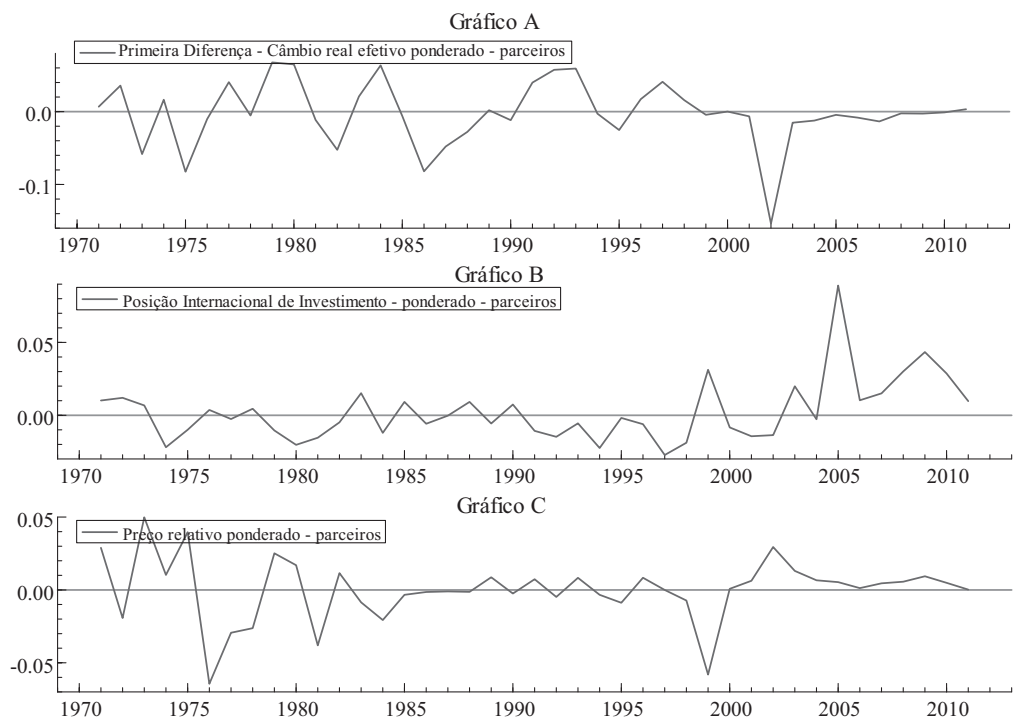

Gráfico 4 - Primeira diferença das séries que compõem o fator brasileiro do VAR-MCEG 


\section{Resultados obtidos}

Nesta seção, apresentam-se os resultados obtidos na presente pesquisa. Em primeiro lugar, são mostrados, de forma detalhada, os resultados do GVECM estimado para dados brasileiros e a medida de desalinhamento cambial construída a partir da mesma. Em seguida, são apresentados os resultados obtidos utilizando a metodologia tradicional. Por fim, comparam-se as duas estimativas.

\subsection{Estimando o modelo GVECM para o Brasil}

A estimação do GVECM é bem parecida com a modelagem de multivariada de cointegração proposta por Johansen e Juselius em diversos trabalhos e sintetizada em dois livros (Johansen, 1995; Juselius, 2009), que são as grandes referências desta abordagem. A abordagem de Pesaran (Dees et al., 2007) e Pesaran et al., 2002) parte da hipótese que as variáveis globais são exógenas fracas com relação aos parâmetros de interesse. O procedimento de modelagem tem de seguir Harbo et al. (1998).

\subsubsection{Testes de cointegração}

Como primeiro passo da análise foram realizados os testes de cointegração multivariados seguindo Johansen (1988) e ajustado para o caso de variáveis exógenas fracas dado por Harbo et al. (1998). Os resultados são apresentados na Tabela 1 e mostram a evidência de um vetor de cointegração significativo a partir das diversas estatísticas e diversas configurações de termos deterministas (tendência linear restrita e constante irrestrita; tendência linear ausente e constante irrestrita; e tendência linear ausente e constante restrita). 


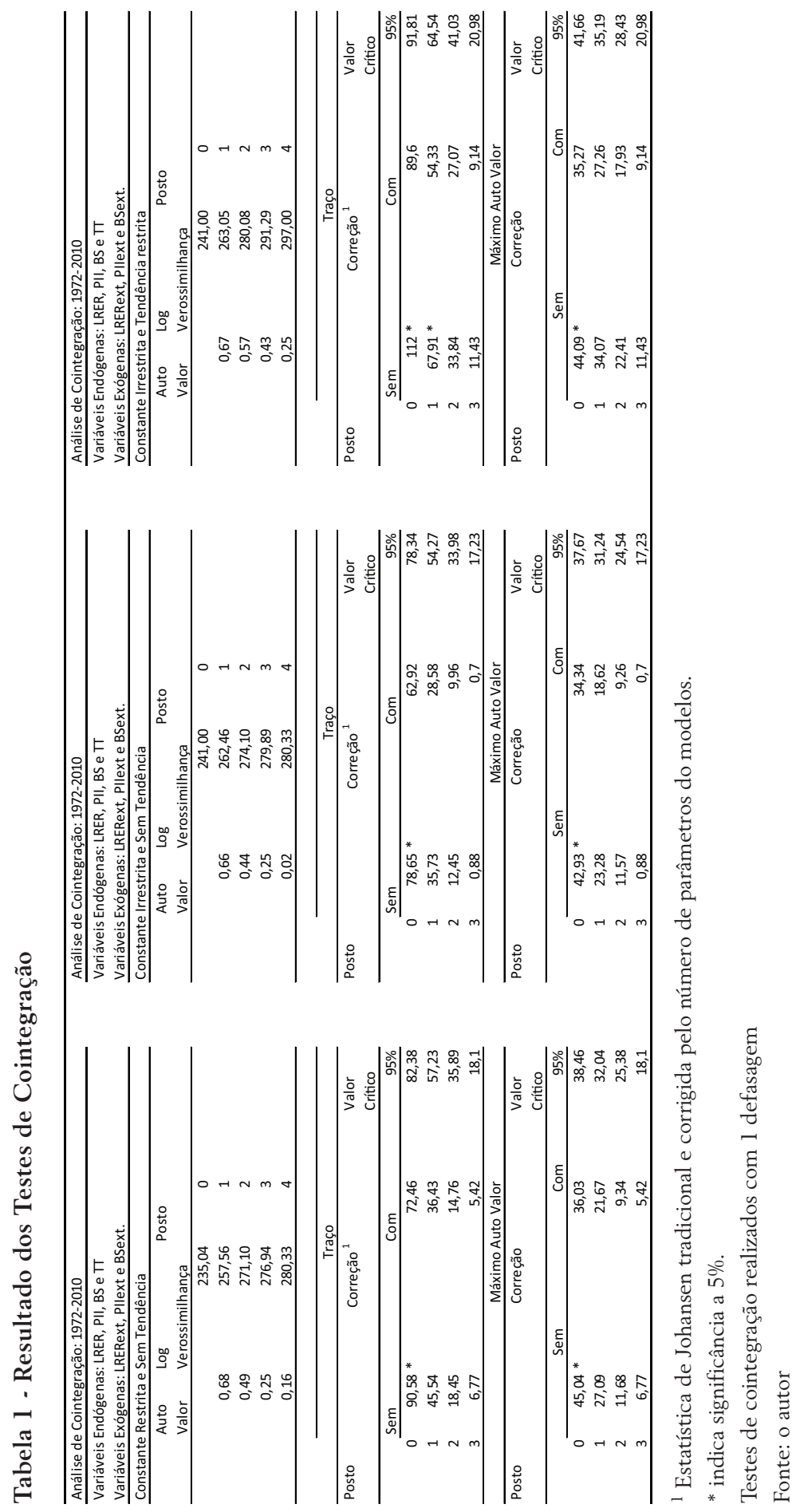




\subsection{Testando algumas simplificações}

Em seguida, foram testadas várias hipóteses sobre os coeficientes do vetor de cointegração, da matriz de cargas e dos componentes deterministas. Em princípio, todos os coeficientes do vetor de cointegração estimado apresentam o sinal esperado pela teoria e magnitudes razoáveis.

O teste de razão de verossimilhança em que se avalia a exclusão de todas as variáveis internacionais do vetor de cointegração permite uma clara rejeição da hipótese nula de que estas não fazem parte da relação de longo prazo, assim como o teste em que as variáveis endógenas que compõem os fundamentos. Pela Tabela 2, os resultados da análise dos critérios de informação também sugerem mesma conclusão. 


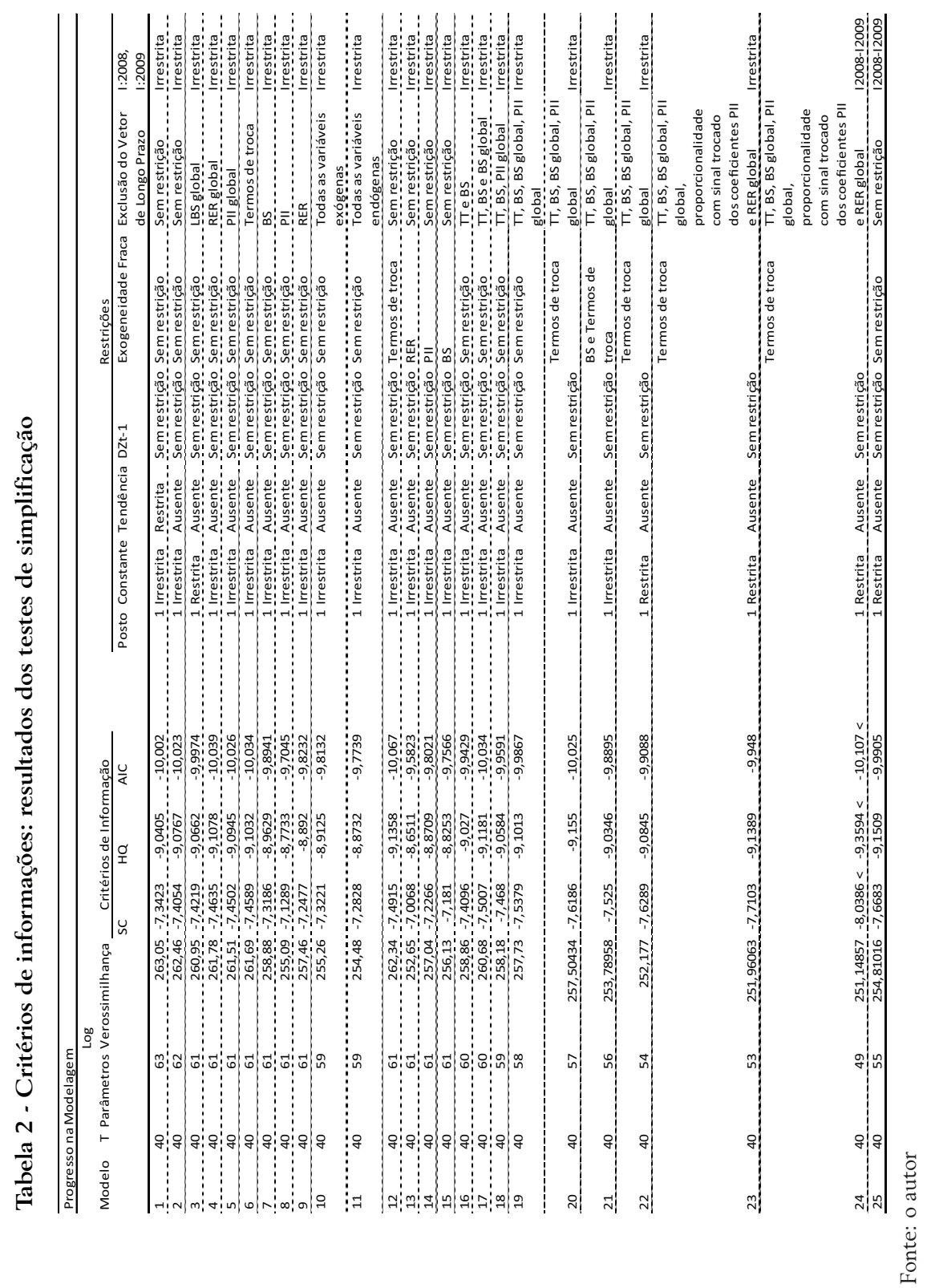


Já quando a taxa de câmbio é excluída do espaço de cointegração, a hipótese nula é rejeitada a partir dos testes de razão de verossimilhança (linha 9 da Tabela 3). Isso fortalece a ideia que o conjunto de variáveis escolhidas explica, no longo prazo, a taxa de câmbio real brasileira e, logo, essas variáveis podem ser interpretadas como fundamentos.

A análise da matriz de cargas sugere que a variável termos de troca é exógena fraca com relação aos parâmetros de interesse. Os testes da Tabela 2 e também da Tabela 3 sugerem que a tendência deve ser excluída do sistema. Já a hipótese que a constante deve estar restrita ao espaço de cointegração também é aceita. Estas duas hipóteses sugerem que nenhuma das variáveis endógenas do sistema teria tendência em nível.

\subsection{Estimando o GVECM final}

O mecanismo de correção de erros correspondente ao modelo 24 é o preferido pelos critérios de informação (Tabela 2) e tido com boa simplificação pelo teste de razão de verossimilhança (Tabela 3) é apresentado abaixo na Equação (7). Os coeficientes estimados no mecanismo de correção de erros estimado sugerem que exista uma relação positiva entre câmbio real brasileiro e posição internacional de investimento e uma relação negativa entre taxa de câmbio real brasileira e taxa de câmbio real dos parceiros comerciais brasileiros. No caso da posição internacional de investimento, uma melhora de $1 \%$ na posição internacional de investimento brasileira como proporção do PIB levará, tudo o mais constante, a uma apreciação de $1,755 \%$ aproximadamente no longo prazo. A evolução temporal do mecanismo de correção de erros é dada no Gráfico 5. A Equação (7) mostra como o mecanismo de correção de erros foi calculado.

$$
M C E_{t}=\text { LRER }_{t}-1,795 * P I_{t}+1,795 * R E R g 20_{t}-3,8916
$$

A Equação (7) também mostra que a evolução do nível da taxa de câmbio real dos parceiros comerciais teria influência sobre a taxa de câmbio real brasileira, ou seja, parte da valorização ou depreciação das moedas dos parceiros comerciais teria de ser acompanhada de movimentos de depreciação e apreciação da moeda brasileira. Esse 
seria o canal pelo qual alterações nos fundamentos dos parceiros comerciais gerariam efeitos sobre a taxa de câmbio real brasileira.

A Tabela 4 apresenta os resultados do modelo final estimado. Utilizou-se o algoritmo de simplificação do Oxmetrics (Hendry e Doornik, 2006; Hendry et al., 2008). O mecanismo de correção de erros é significativo em todas as equações. A variável primeira diferença do logaritmo dos termos de troca é incluída, de forma contemporânea, no sistema, dado o status de exogeneidade fraca desta variável, que se mostra significativa na equação da posição internacional de investimento com sinal positivo - Tabela 4. Uma possível explicação para esse resultado está relacionada com o efeito positivo que um ganho de termos de troca pode gerar sobre as contas externas. Esse ganho implicaria melhoria do resultado de conta corrente que, acumulado ao longo do tempo, geraria melhorias na posição internacional de investimentos de um país.

O efeito que termos de troca gera sobre a taxa de câmbio real é indireto. Não há cointegração entre as variáveis, todavia uma melhora de termos de troca provoca uma melhoria na variável posição internacional de investimento. Essa melhoria, tudo o mais constante, induz a uma valorização da moeda brasileira. Dessa forma, o que o presente trabalho sugere não é que termos de troca não importam para a taxa de câmbio. O que se sugere é que o efeito se dá de forma indireta e na direção intuitiva.

O mecanismo de correção de erros é diretamente proporcional ao desalinhamento cambial, pois o sistema possui um vetor de cointegração, e a decomposição de Gonzalo e Granger é utilizada. O mecanismo de correção de erros tem um coeficiente negativo na equação da taxa de câmbio real, mostrando que os desvios do equilíbrio são corrigidos através desta equação, o que reforça a ideia de que o vetor de cointegração possa ser associado ao desalinhamento cambial. Além disso, o mecanismo de correção de erros tem sinal negativo na equação da posição internacional de investimento, o que implica que um desalinhamento cambial positivo, o câmbio excessivamente forte, gera um efeito de piora na posição internacional de investimento. Por esse canal, o efeito seria desestabilizador e ampliaria o desequilíbrio.

Como o sistema é estável, a correção ao equilíbrio dá-se pelas demais equações. Resultado similar foi obtido por Nilsson (2004) para a Suécia, por exemplo. O mecanismo de correção de erros também gera efeitos sobre a evolução da variável preço relativo, mas não mostrou-se relevante no longo prazo para explicar a taxa de câmbio real. 


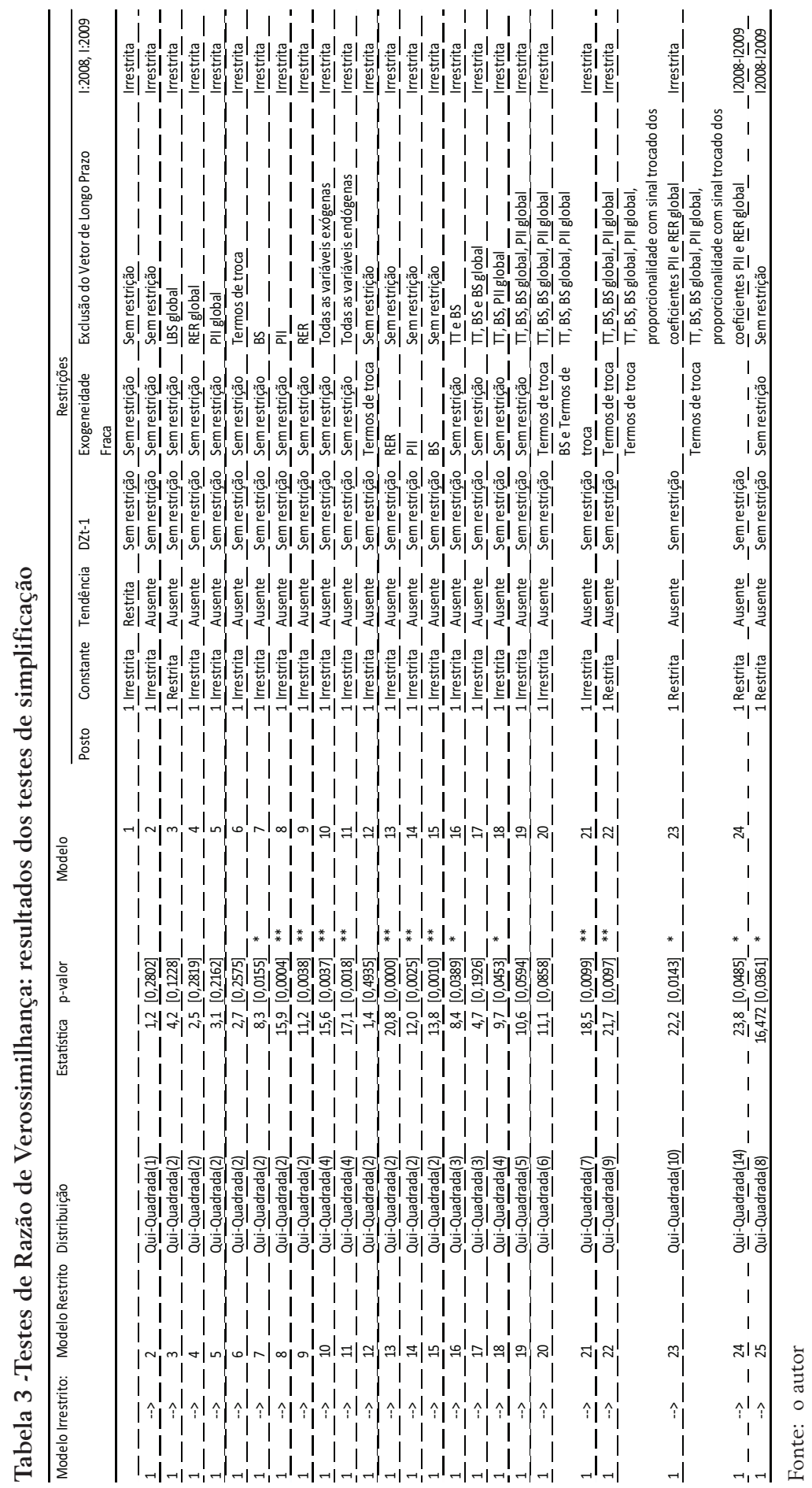


Tabela 4 - Modelo condicional estimado

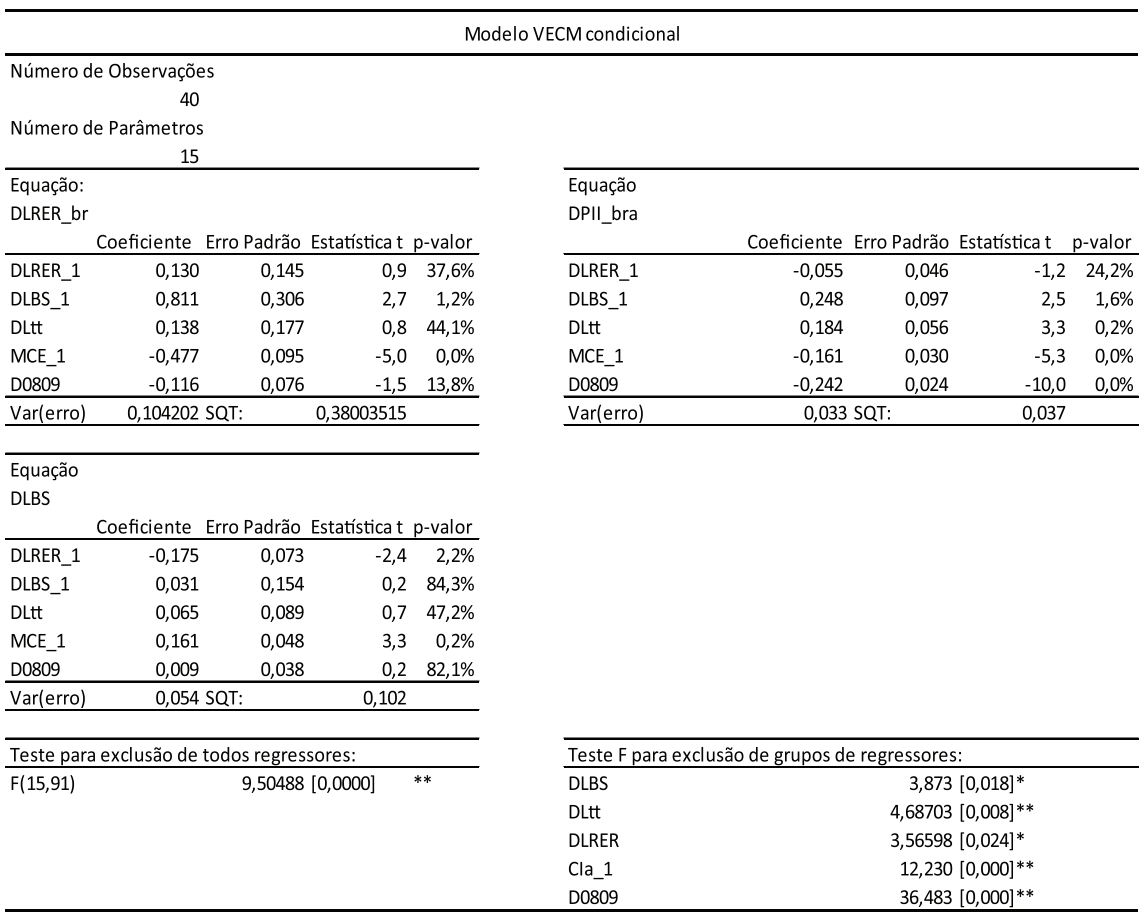

Fonte: o autor

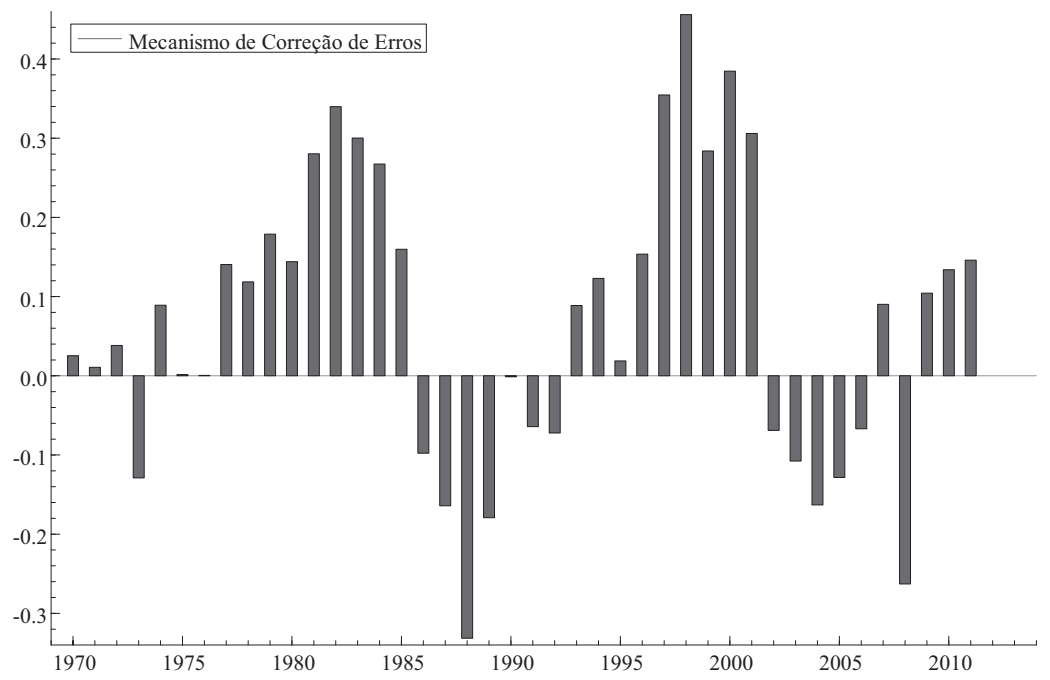

Gráfico 5 - Mecanismo de correção de erros

Fonte: o autor 


\subsection{Estimando o desalinhamento cambial}

A partir dos parâmetros do modelo apresentado na 4, é possível construir uma estimativa de desalinhamento cambial. Utilizando a decomposição de Gonzalo e Granger, é possível estimar o desalinhamento cambial a partir das expressões descritas a seguir.

O componente transitório é dado pela Equação (8):

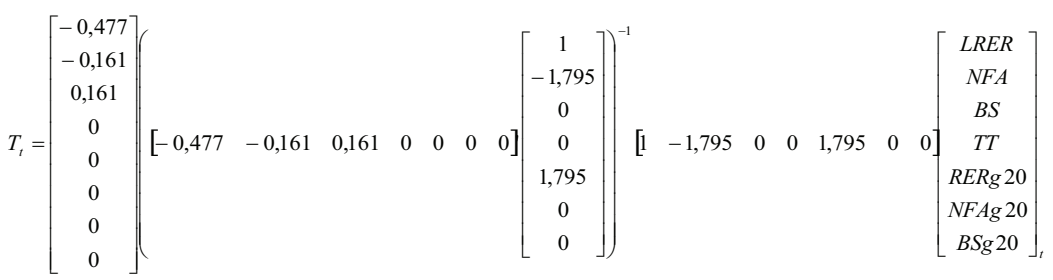

O componente permanente é dado pela Equação (9):

$G G_{t}=X_{t}-T_{t}=\left[\begin{array}{c}\text { LRER } \\ N F A \\ B S \\ T T \\ R E R g 20 \\ N F A g 20 \\ B S g 20\end{array}\right]_{t}\left[\begin{array}{c}-0,477 \\ -0,161 \\ 0,161 \\ 0 \\ 0 \\ 0 \\ 0 \\ 0\end{array}\right](-0,18795)^{-1} E C M_{t}$

Por fim, o desalinhamento cambial pode ser obtido a partir da seguinte conta:

$$
\text { desalinhamento }_{t}=((-0,477) /(-0,18795)) E C M_{t}
$$

Por exemplo, no ano de 2011, o valor do mecanismo de correção de erros calculado a partir da Equação (7) é 0,1460.

Esse valor deve ser multiplicado por 2,537869*(0,1460) $=0,37057$. Como os dados estão em logaritmo neperiano, o desalinhamento seria da ordem de 44,85\% (= $\exp (0,37057)-1)$. A mesma conta deve ser feita para os valores do mecanismo de correção de erros nos demais anos. O Gráfico 6 mostra a evolução do desalinhamento cambial brasileiro estimado para todos os períodos da amostra. 


\subsection{Avaliando o status de exogeneidade fraca}

A hipótese de exogeneidade fraca é essencial para que os resultados descritos na seção anterior sejam válidos. Dessa forma, procedeu-se à estimação dos modelos marginais incorporando o vetor de cointegração estimado. Utilizando o algoritmo de seleção de modelos do Oxmetrics, foi possível excluir o vetor de cointegração estimado de todos os modelos marginais. ${ }^{10}$ Isso fortalece as conclusões obtidas a partir do modelo condicional descrito nas seções anteriores. Os modelos marginais compreendem todas as variáveis internacionais, mais a série de termos de troca.

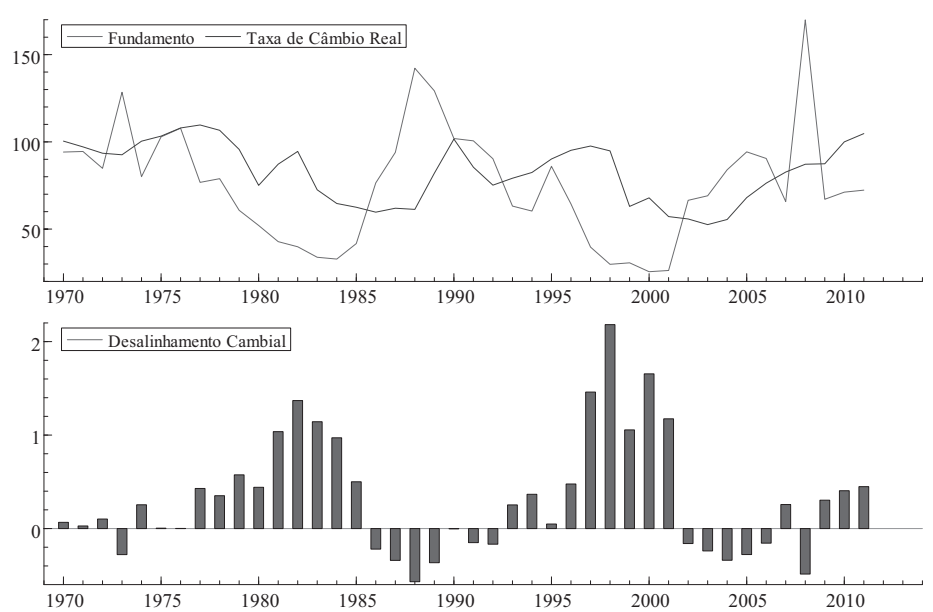

Gráfico 6 - Desalinhamento cambial, fundamentos e taxa de câmbio real Fonte: o autor.

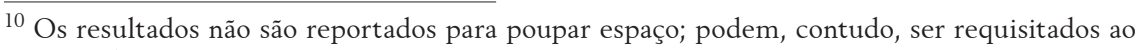
autor diretamente. 


\subsection{Comparação com a modelagem tradicional}

Realizou-se o procedimento tradicional, similar ao da seção anterior, utilizando apenas as variáveis do país: taxa de câmbio real, posição internacional de investimento, fator Balassa-Samuelson e termos de troca.

O modelo preferido possui o seguinte mecanismo de correção de erros:

$$
M C E_{2 t}=L_{R E R_{t}}-1,98 * N F A_{t}-0,42
$$

A partir do VECM estimado, pode-se calcular uma estimativa de desalinhamento. $\mathrm{O}$ componente transitório é dado pela Equação (12). Assim como no modelo global, as variáveis associadas ao efeito Balassa-Samuelson e termos de troca não se mostraram significativas na relação de longo prazo: ${ }^{11}$

$$
T T_{2 t}=\left[\begin{array}{c}
-0,32528 \\
0 \\
0 \\
0
\end{array}\right]\left(\left[\begin{array}{llll}
-0,32528 & 0 & 0 & 0
\end{array}\right]\left[\begin{array}{c}
1 \\
-1,98 \\
0 \\
0
\end{array}\right]\right)^{-1}\left[\begin{array}{llll}
1 & 0 & 0 & 0
\end{array}\right]\left[\begin{array}{c}
L R E R \\
N F A \\
B S \\
T o T
\end{array}\right]_{t}
$$

O componente permanente é dado pela Equação (12):

$$
G G_{2 t}=X_{t}-T T_{2 t}=\left[\begin{array}{c}
L R E R \\
N F A \\
B S \\
T o T
\end{array}\right]_{t}-\left[\begin{array}{l}
1 \\
0 \\
0 \\
0
\end{array}\right] E C M_{t}
$$

Por fim, o desalinhamento cambial pode ser obtido a partir de:

$$
\text { desalinhamento }_{t}=E C M_{2 t}
$$

\footnotetext{
${ }^{11}$ Os resultados podem ser requisitados ao autor diretamente; não são reportados para poupar espaço.
} 
O Gráfico 7A apresenta o desalinhamento cambial estimado a partir da metodologia tradicional em que variáveis externas não são incluídas. Esta abordagem é a proposta em Alberola et al. (1999).

Já no Gráfico 7B apresenta-se a comparação das estimativas de desalinhamento cambial. Como era de se esperar, existe uma associação positiva entre as duas medidas. Contudo, há uma diferença expressiva quanto à magnitude para alguns pontos. A grande diferença entre as metodologias está no grau de desalinhamento cambial estimado para o período de 1995 a 2001. Pela modelagem tradicional, a taxa de câmbio real brasileira oscilou entre um discreto desalinhamento cambial positivo e negativo. Pela metodologia de GVECM, a moeda brasileira teria apresentado um período de expressiva valorização. Vale lembrar que, neste período, a economia brasileira apresentou elevados déficits em transações correntes como proporção do PIB com um regime cambial praticamente fixo e com baixo nível de reservas (Gráfico 8).
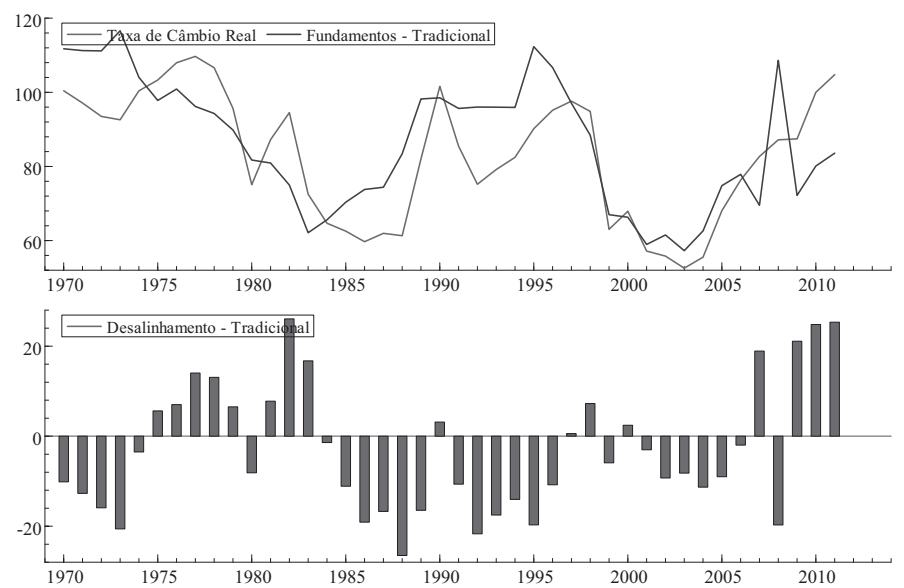

Gráfico 7 - Desalinhamento cambial, fundamentos e taxa de câmbio real: metodologia tradicional

Fonte: o autor. 


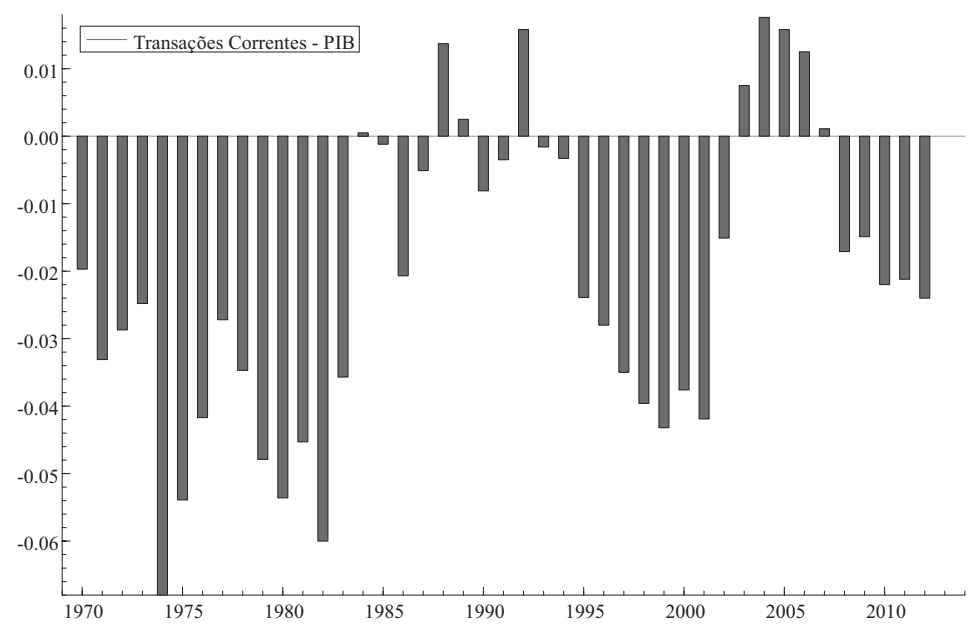

Gráfico 8 - Resultado de transações correntes como proporção do PIB brasileiro Fonte: o autor.

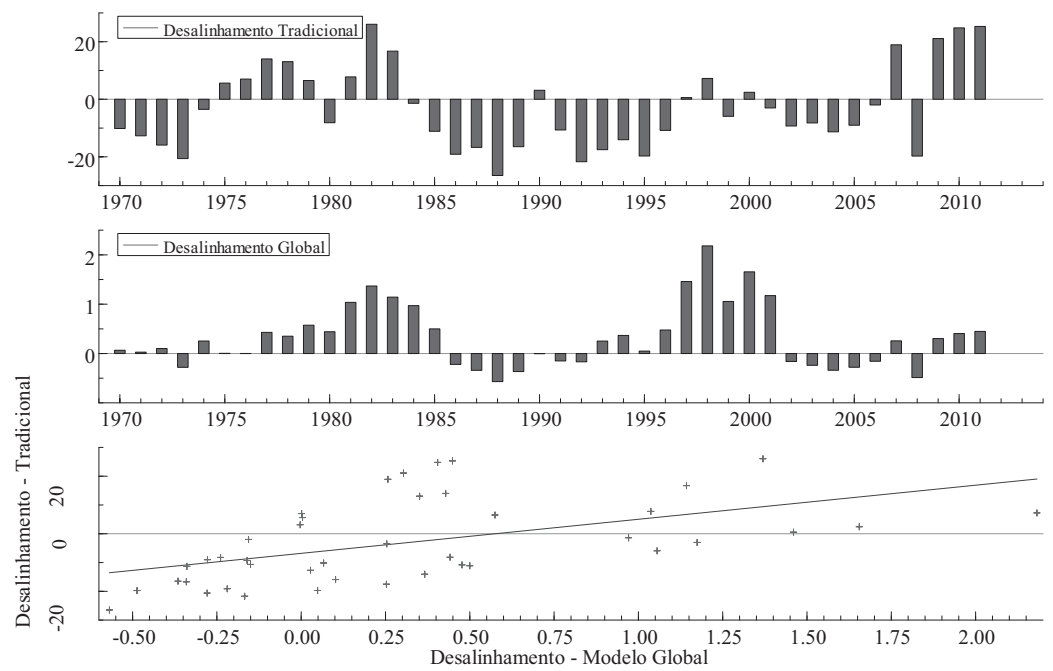

Gráfico 9 - Desalinhamento cambial, fundamentos e taxa de câmbio real: comparação de metodologias

Fonte: o autor. 


\subsection{Comparação com a Literatura}

Os trabalhos de Willianson e Cline no Petersen Institute (Cline, 2008; Cline e Williamson, 2007; Williamson e Cline, 2012; Cline e Williamson, 2011) e o Pilot Report recentemente divulgado pelo FMI (IMF, 2012) utilizam uma abordagem diferente da apresentada no trabalho. Os autores dos trabalhos citados utilizam para construir suas estimativas de desalinhamento cambial o resultado em conta corrente.

Tendo em vista comparar as diferentes metodologias, o Gráfico 9 se subdivide em três. O Gráfico 9A mostra a evolução do desalinhamento cambial estimado e o resultado de transações correntes. $\mathrm{O}$ Gráfico 9B mostra que existe uma associação negativa entre a medida de desalinhamento cambial e o resultado em transações correntes. O Gráfico 9C sugere que os momentos em que a medida de desalinhamento cambial aponta para uma moeda forte coincidem com resultados piores em transações correntes. Em momentos em que a moeda estaria fraca, há resultados melhores em transações correntes. Em suma, a metodologia aqui apresentada está em linha com o princípio defendido pelo FMI e o Petersen Institute, no sentido de que o resultado de transações correntes estaria diretamente ligado ao desalinhamento.

Os trabalhos de Marçal (2011) e Marçal e Barbi (2010) estimaram o desalinhamento brasileiro utilizando a metodologia de Vetores Autorregressivos com Correção de Erros e a decomposição de Gonzalo e Granger. O primeiro trabalho utiliza dados trimestrais com as variáveis taxa de câmbio real, posição internacional de investimento, termos de troca e indicador para controlar o efeito BalassaSamuelson. O segundo trabalho segue a mesma direção, mas utiliza um modelo com quebra estrutural. Outro exemplo de estudo que analisa o caso brasileiro é Damasceno e Vieira (2012).

O presente trabalho restringiu-se ao caso brasileiro, o que por si só, até onde é de conhecimento do autor, é uma inovação. A metodologia de Pesaran pode ser aplicada a todos os conjuntos de países listados. Essa tarefa é deixada para pesquisas futuras. Outra opção seria a utilização de VECM com painel longo em linhas de Groen e Kleibergen (2003), Larsson e Lyhagen (2007), entretanto a amostra na dimensão temporal impede a utilização de tal técnica para um 
grupo grande de países. A metodologia do GVECM, ao partir da análise dos países com fatores globais, para então construir o modelo global, evita esse problema.

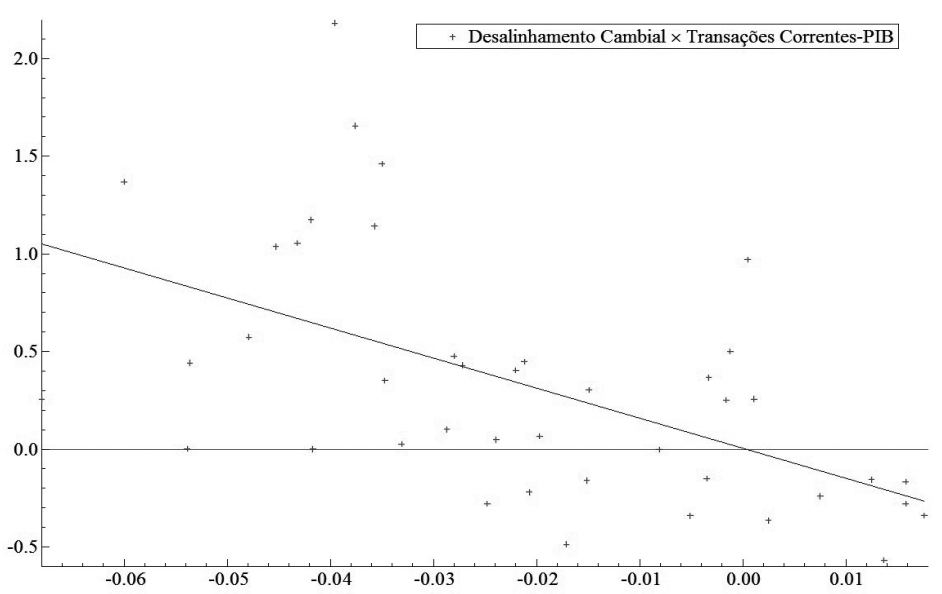

Gráfico 10 - Desalinhamento cambial brasileiro - modelo global e transações correntes

Fonte: o autor.

\section{Conclusões}

O presente trabalho teve como por objetivo comparar duas metodologias para cálculos de desalinhamento. A primeira consiste na estimação do desalinhamento cambial a partir de técnicas multivariadas de séries de tempo, nas quais apenas variáveis associadas ao país são utilizadas na modelagem. A segunda consiste na utilização de fatores globais como sugerido pelo modelo Vetorial Autorregressivo com Correção de Erros Global (GVECM). O caso brasileiro foi utilizado como exemplo, analisado a partir das duas metodologias.

Os resultados sugerem que as estimativas podem diferir em magnitude para diferentes períodos. Ambas as metodologias sugerem que o canal pelo qual termos de troca afeta a taxa de câmbio real brasileiro é indireto. Melhorias de termos de troca levam à melhoria da posição internacional de investimento e, logo, geram uma valorização da moeda brasileira. 
O trabalho também sugere que a evolução dos fundamentos dos principais parceiros comerciais brasileiros, ao condicionar os movimentos de longo prazo das taxas de câmbio reais efetivas destes países, gera repercussão sobre o equilíbrio brasileiro. O trabalho sugere, ainda, que a aplicação da metodologia de GVECM é um ponto importante de pesquisa a ser trilhado, embora pouco explorado na literatura de desalinhamento cambial.

\section{Referências}

AHMAD, Y.; CRAIGHEAD, W. D. Temporal aggregation and purchasing power parity persistence. Journal of International Money and Finance, 2010. In Press, Accepted Manuscript.

ALBEROLA, E. et al. Global equilibrium exchange rate: euro, dolar, ins, outs and other major currencies in a painel cointegration framework. Washington: IMF, 1999 (IMF Working Paper, n. 99-175).

BALASSA, B. The Purchasing power doctrine: a reappraisal. Journal of Political Economy, v. 72, 1964, p. 584-596.

BEVERIDGE, S.; NELSON, D. B. A new approach to decomposition of economic time series into permanent and transitory components with particular attention to measuremente of the business cycle. Journal of Monetary Economics, v. 7, n. 2, 1981, p. 151-174.

BILSON, J. F. Recent developments in monetary models of exchange rate determination. IMF staff paper, n. 26, v. 2, 1979, p. 201-223.

CLARK, P. B.; MAcDONALD, R. Exchange rates and economic fundamentals: a methodological comparison of BEERs and FEERs. International Monetary Fund, 1998.

CLINE, W. R. Estimating consistent fundamental equilibrium exchange rate. Washington: Peterson Institute for International Economics, 2008. p. 1-26 (Working Paper Series).

CLINE, W. R.; WILLIAMSON, J. Estimates of the equilibrium exchange rate of the Renminbi: is there a consensus and, if not, why not? Conference on china's exchange rate policy. Washington: Peter Institute for International Economics, 2007.

. The current currency state situation. Policy brief, Peter Institute, 2011. p. 11-18.

DAMASCENO, A.; VIEIRA, F. Taxa de Câmbio de Equilíbrio e Desalinhamento Cambial: Evidências para o Brasil (1994-2011); Anais do 40 Encontro Nacional da ANPEC, Porto de Galinhas, BA, 2012 Disponível em: http://www.anpec.org.br/encontro/2012/inscricao/files_I/i6-f59c5c54f822eb022240618b483fc08a.pdf

DEES, S. et al. Exploring the international linkages of the euro area: a global VAR analysis. Journal of applied econometrics, v. 22, n. 1, 2007, p. 1-38.

DORNBUSCH, R. Expectations and exchange rate dynamics. Journal of Political Economy, v. 84, n. 6, 1976, p. 1.161-1.176.

EDWARDS, S. Exchange rate misaligment in developing countries. NBER, 1987 (Working Paper, n. 442 ).

EICHENGREEN, B.; SACHS, J. D. Exchange rates and economic recovery in the 1930s. Cambridge, Mass.:National Bureau of Economic Research, 1986.

FARUQEE, H. Long-run determinants of the real exchange rate: a stock flow perspective. IMF staff paper, n. 42, 1995, p. 80-107.

Estud. Econ., São Paulo, vol.45, n.3, p.593-623, jul.-set. 2015 
FROOT, K. A.; ROGOFF, K. (Ed.). Perspectives on PPP and long-run real exchange rates. Handbook of international economics. Amsterdam: North-Holland, 1995.

GLICK, R.;. ROSE, A. K. Contagion and trade: why are currency crises regional? Washington: NBER, 1998 (NBER Working Paper, n. 6.806).

GONZALO, J.; GRANGER, C. W. J. Estimation of common long-memory components in cointegrated systems. Journal of Business and Economics Statistics, v. 13, n. 1, 1995.

GROEN, J. J. J.; KLEIBERGEN, F. Likelihood-based cointegration analysis in painels of vector error-correction models. American Statistical Association, v. 21, 2003, p. 295-318.

HARBO, I. et al. Asymptotic inference on cointegrating rank in partial systems. Journal of Business \& Economic Statistics, v. 16, n. 4, 1998, p. 388-399.

HENDRY, D.F. and DOORNIK, J.A. Modelling Dynamic Systems Using PcGive. Vol. I. 2006, London.

HENDRY, D. et al. Automatic selection of indicators in a fully saturated regression. Computational Statistics, v. 23, n. 2, 2008, p. 337-339.

HENDRY, D. F. Dynamic econometrics. Oxford: Oxford University Press, 1995.

HOSSFELD, O. Equilibrium real exchange rates and real exchange rate misaligments: time series vs. painel estimates. Austria, 2009 (FIW Working Paper Series, n. 06).

IMF - INTERNATIONAL MONETARY FUND. Pilot external sector report. IMF, 2012.

JOHANSEN, S. Statistical analysis of cointegration vectors. Journal of Economic Dynamics and Control, v. 12, n. 2,1988 , p. $231-254$.

Likelihood-based inference in cointegrated vector autoregressive models. Oxford: Oxford University Press, 1995.

JUSELIUS, K. The cointegrated VAR model methodology and applications. Oxford: Oxford University Press, 2009.

KASA, K. Common stochastic trends in international stock markets. Journal of Monetary Economics, v. 29, p. 95-124, 1992.

KUBOTA, M. Real exchange rate misalignments: theoretical modelling and empirical evidence. York: University of York, 2009 (Discussion Papers in Economics).

KUBOTA, M. Real exchange rate misaligments. York: University of York, Departament of Economics, 2009 (Phd: 201).

LANE, P. R.; MILESI-FERRETTI, G. M. The external wealth of nations mark II: revised and extended estimates of foreign assets and liabilities, 1970-2004. Journal of International Economics, v. 73, n. 2, 2007, p. 223-250.

LARSSON, R.;LYHAGEN, D. J. Inference in painel cointegration models with long painels. Journal of Business and Economic Statistics, v. 25, n. 4, 2007, p. 473-483.

MARÇAL, E. F. Estimando o desalinhamento cambial brasileiro a partir de modelos multivariados com cointegração. Brasília: Ipea, 2011(Texto para Discussão, n. 1.666).

MARÇAL, E. F.; BARBI, F. Quo Vadis real? Estimating the Brazilian real exchange rate misalignment in vector error correction model with structural change. Social science research network (SSRN), São Paulo, 2010.

MARÇAL, E. F. et al. Evalutaion of contagion or interdependence in the financial crises of Asia and Latin America considering macroeconomic fundamentals. Applied Economics, v. 43, n. 19, 2011, p. 2.365-2.379.

MEESE, R. A.; ROGOFF, K. Empirical exchange models of the seventies: do they fi out of the sample? Journal of International Economics, v. 14, 1983, p. 3-24.

MUSSA, M. The exchange rate, the balance of payments and monetary policy under a regime of controlled floating. Scadinavian Journal of Economics, v. 78, 1976, p. 228-248. 
NILSSON, K. Do fundamentals explain the behaviour of the Swedish real effective exchange rate? Scandinavian Journal of Economics, v. 106, n. 4, 2004, p. 603-622.

PESARAN, M. H. e SCHUERMANN, T. e WEINER, T. Modelling regional interdependencies using a global error-correcting macroeconomic model. Cambridge: University of Cambridge, Department of Applied Economics, 2001.

PESARAN, M. H. e SCHUERMANN, T. e WEINER, T. Modeling regional interdependecies using a global error-correcting macroeconometric model. Journal of Business and Economics Statistics, v. 22, 2002.

PESARAN, M. H.; SMITH, R. Macroeconomic modelling with a global perspective. Cambridge: University of Cambridge, Faculty of Economics, 2006.

SAMUELSON, P. Theoretical notes on trade problems. The Review of Economics and Statistics, v. 46, 1964, p. 145-154.

STEIN, J. The fundamental determinants of the real exchange rate of the U.S. dollar relative to other G-7 currencies. IMF, 1995 (IMF Working Paper).

TAYLOR, A. M. Potential pitfalls for the purchasing-power-parity puzzle? Sampling and specification biases in mean-reversion tests of the law of one price. Econometrica, v. 69, n. 2, 2001, p. 473-498.

TURNOVSKY, S. J. et al. Dynamic strategic monetary policies and coordination in interdependent economies. Washington: NBER, 1987 (NBER Working Paper, n. 2.467).

UGAI, H. Effects of the quantitative easing policy: a survey of empirical analyses. Monetary and Economic Studies, Bank of Japan, v. 25, n. 1, 2007, p. 1.

WILLIAMSON, J. Estimating equilibrium exchange rates. Washington D.C.: IIE, 1994.

WILLIAMSON, J.; Cline, W. R. Estimates of fundamental equilibrium exchange rates. Washington: Peterson Institute for International Economics, 2012. p. 12-14. 